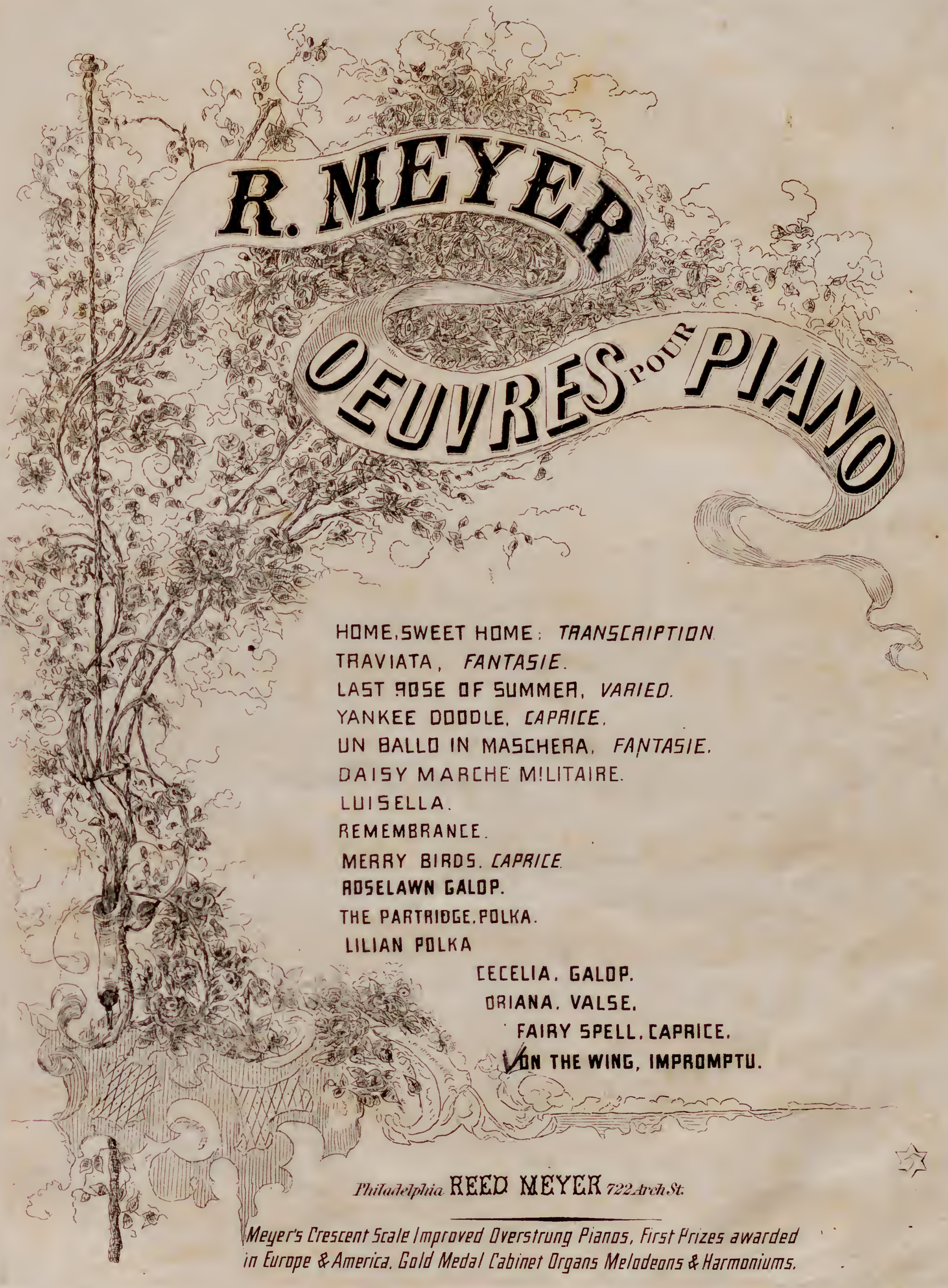


W m:S.Triebels Esq: of Philadelphia.

\section{ON THE WING.}

I M P R O M P T

R EED MEY Ë .
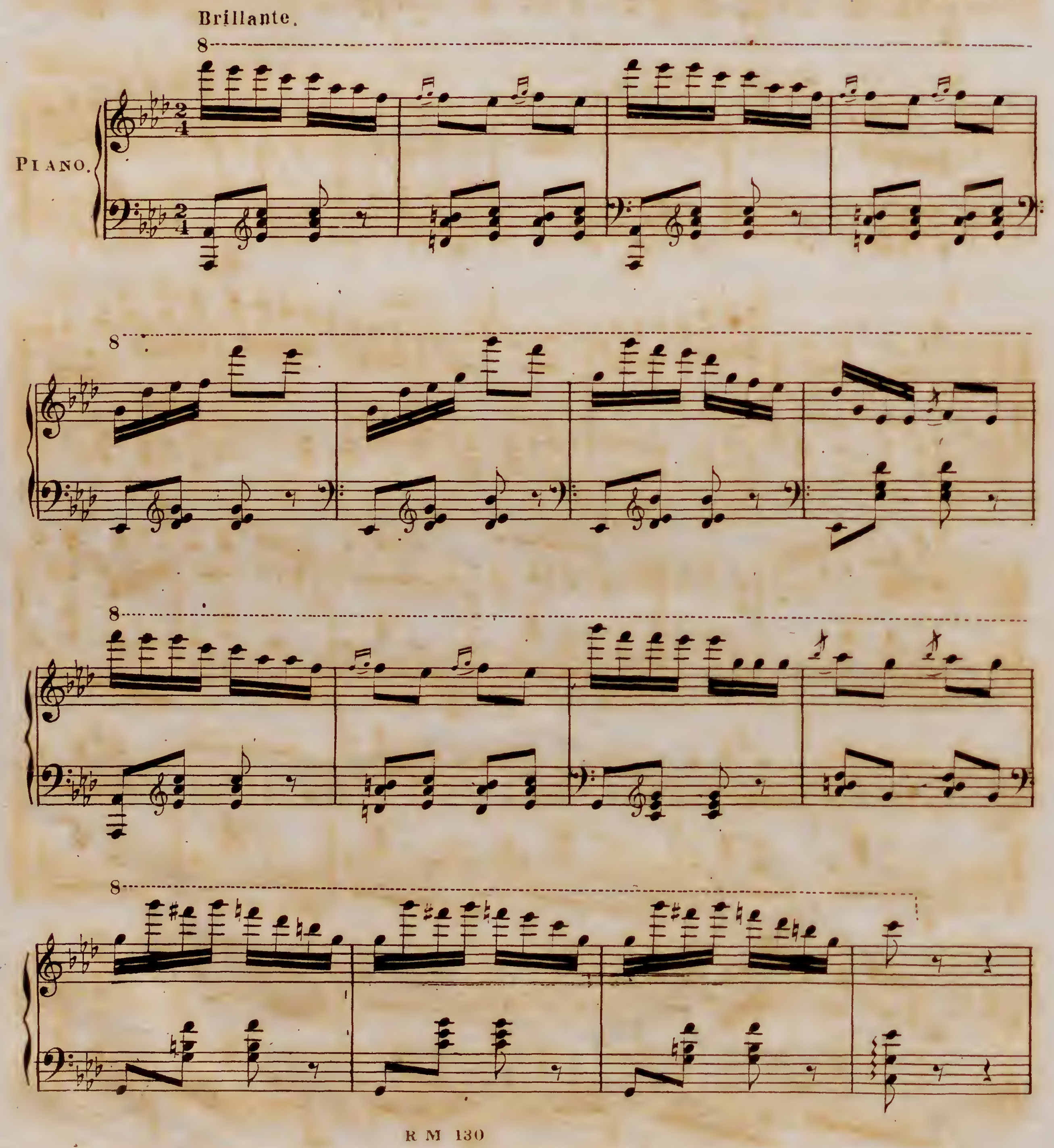

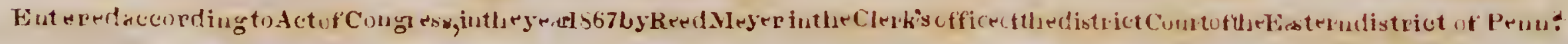



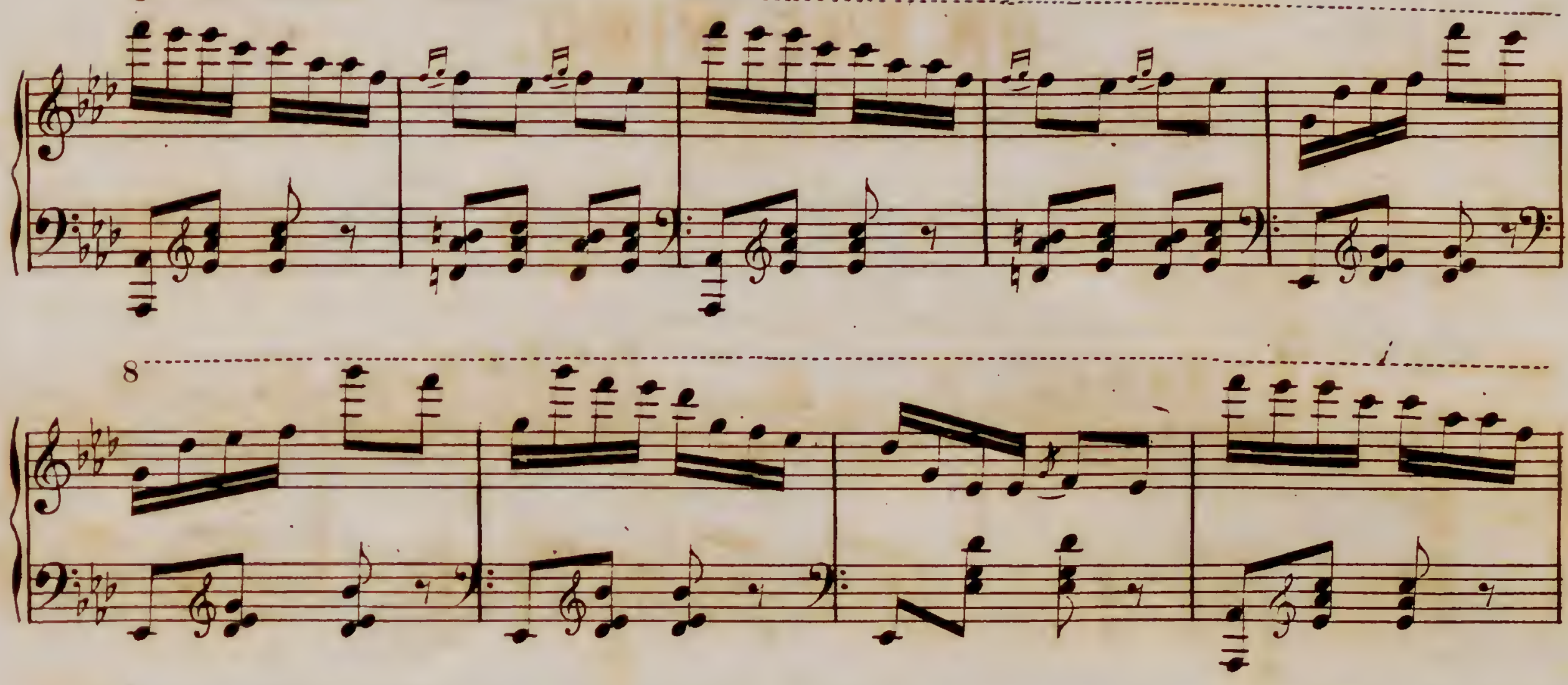

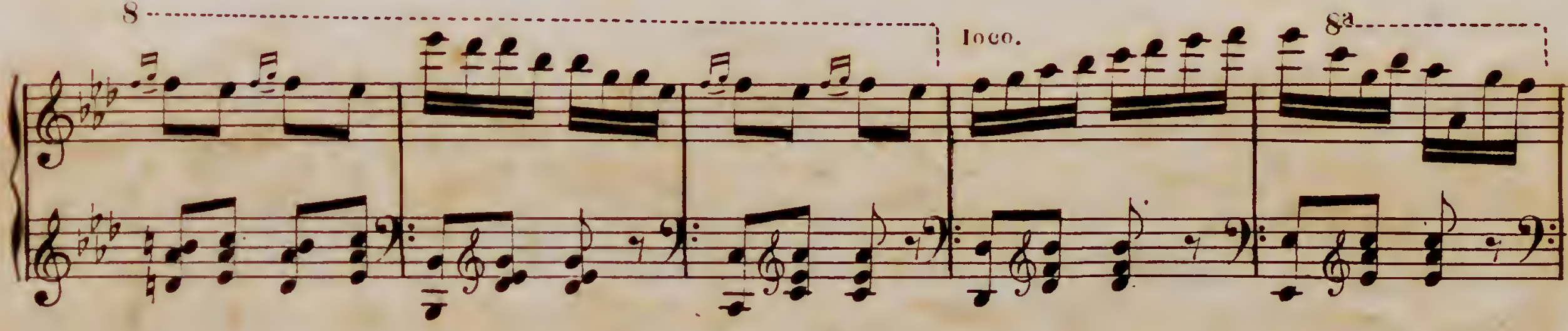
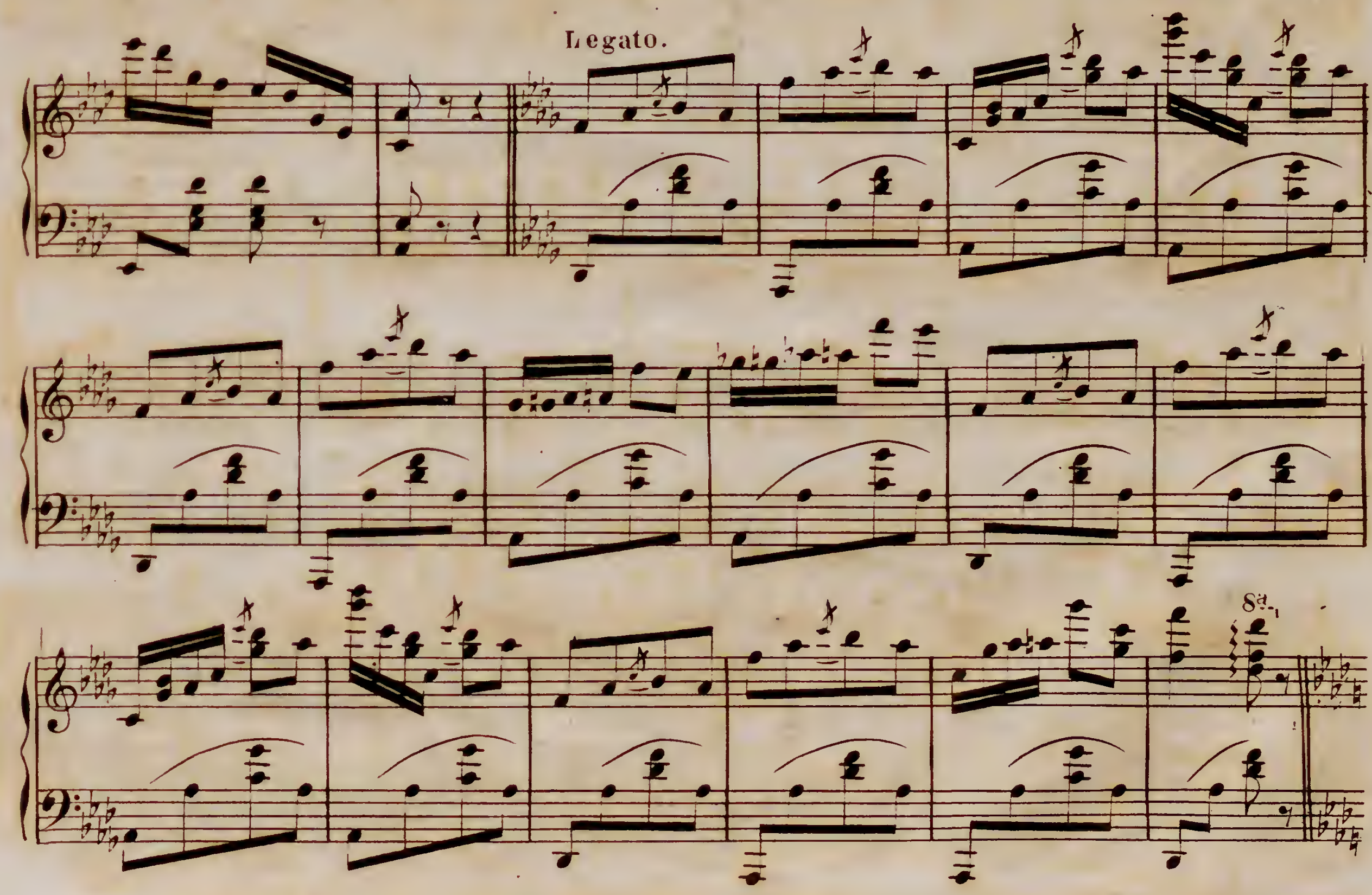

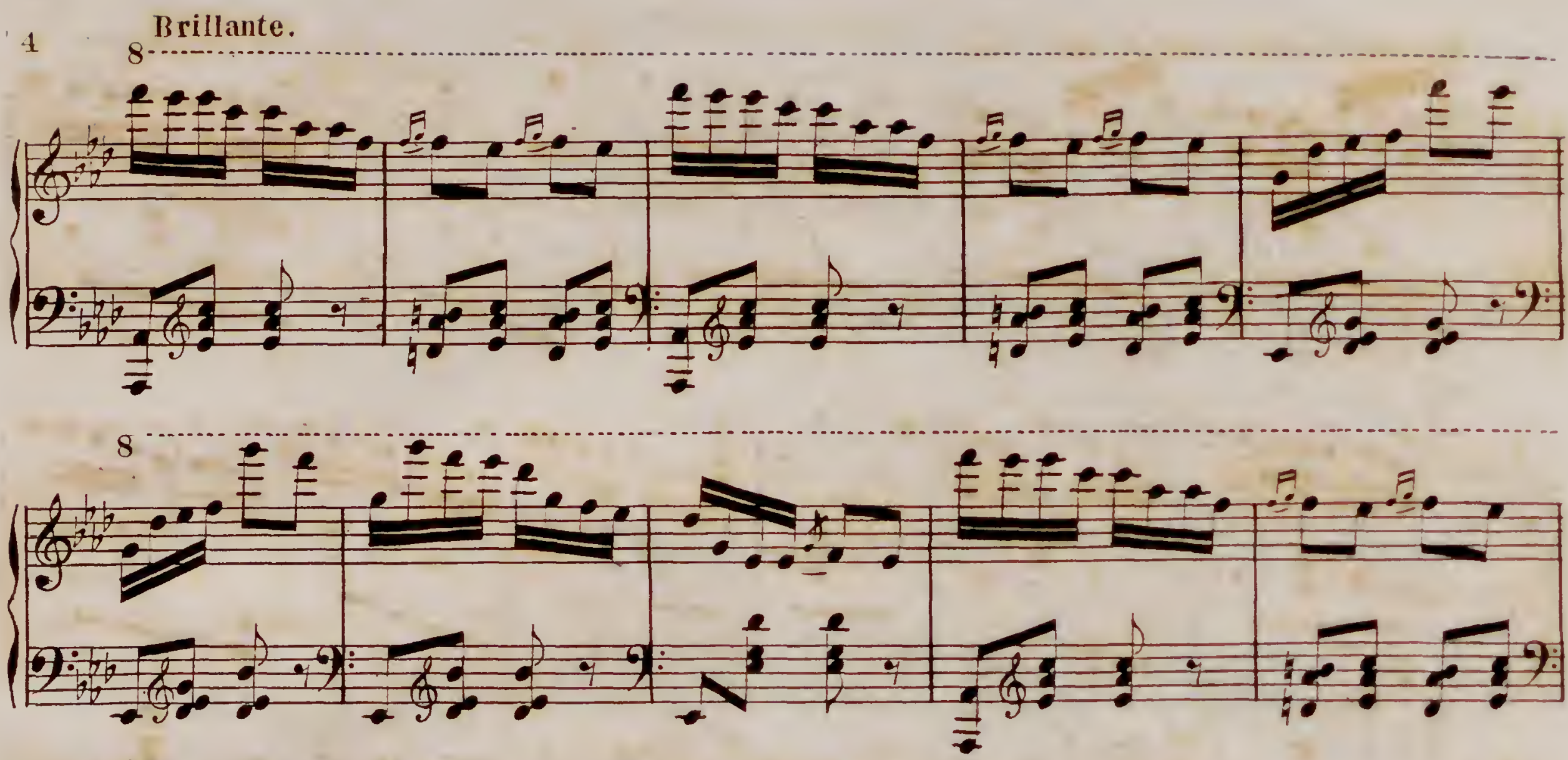

8.

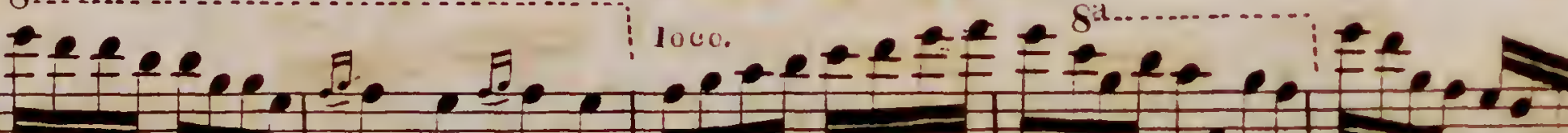

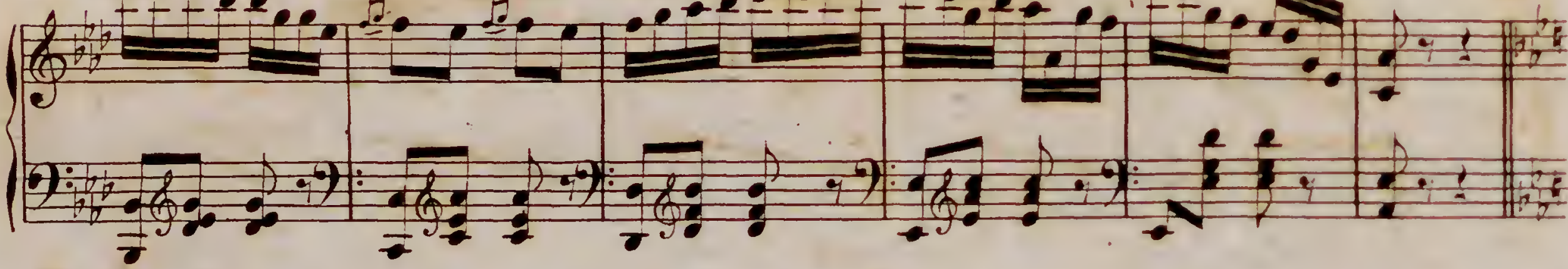

Con gusto.
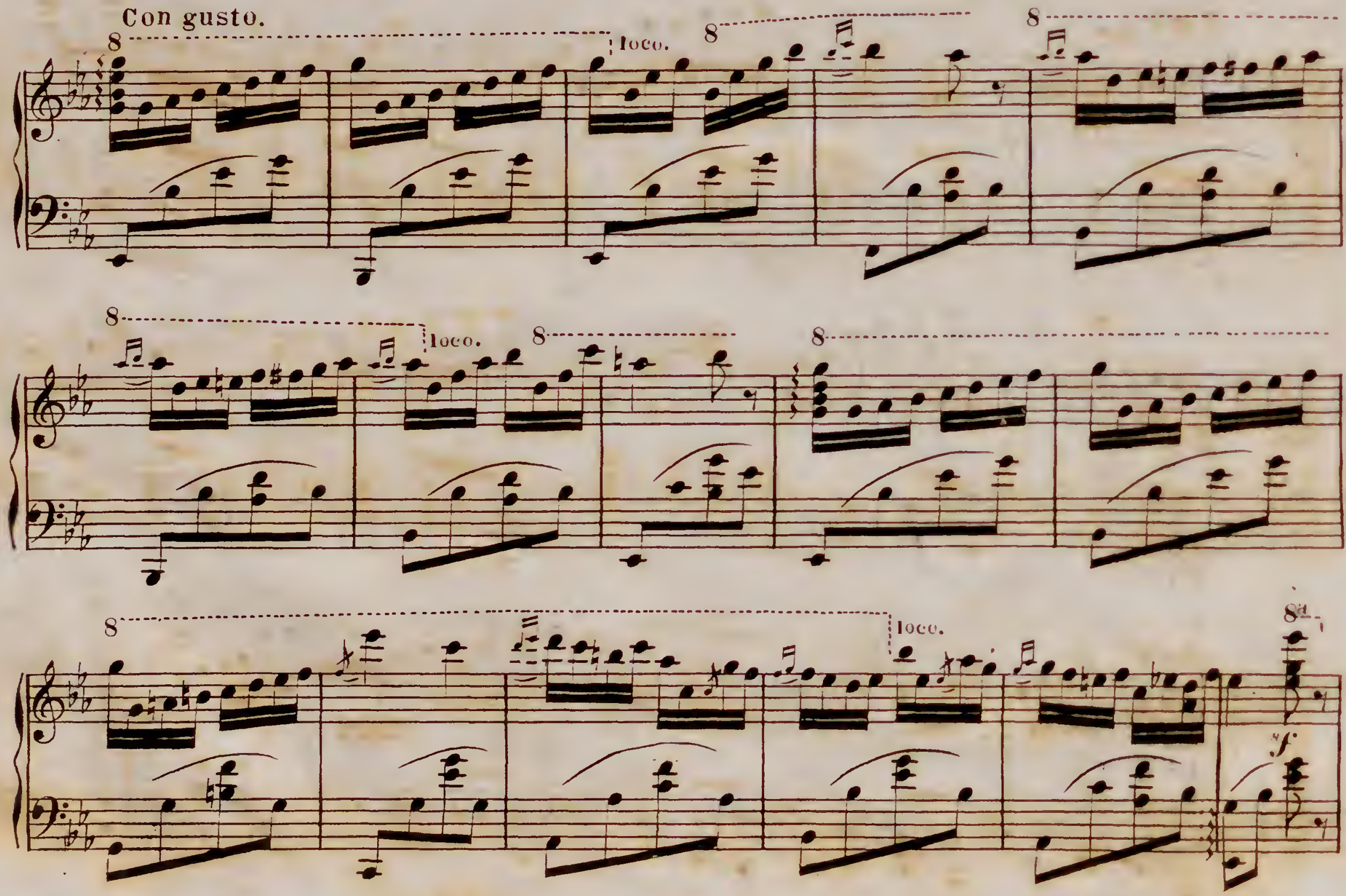

R NT 130 
5
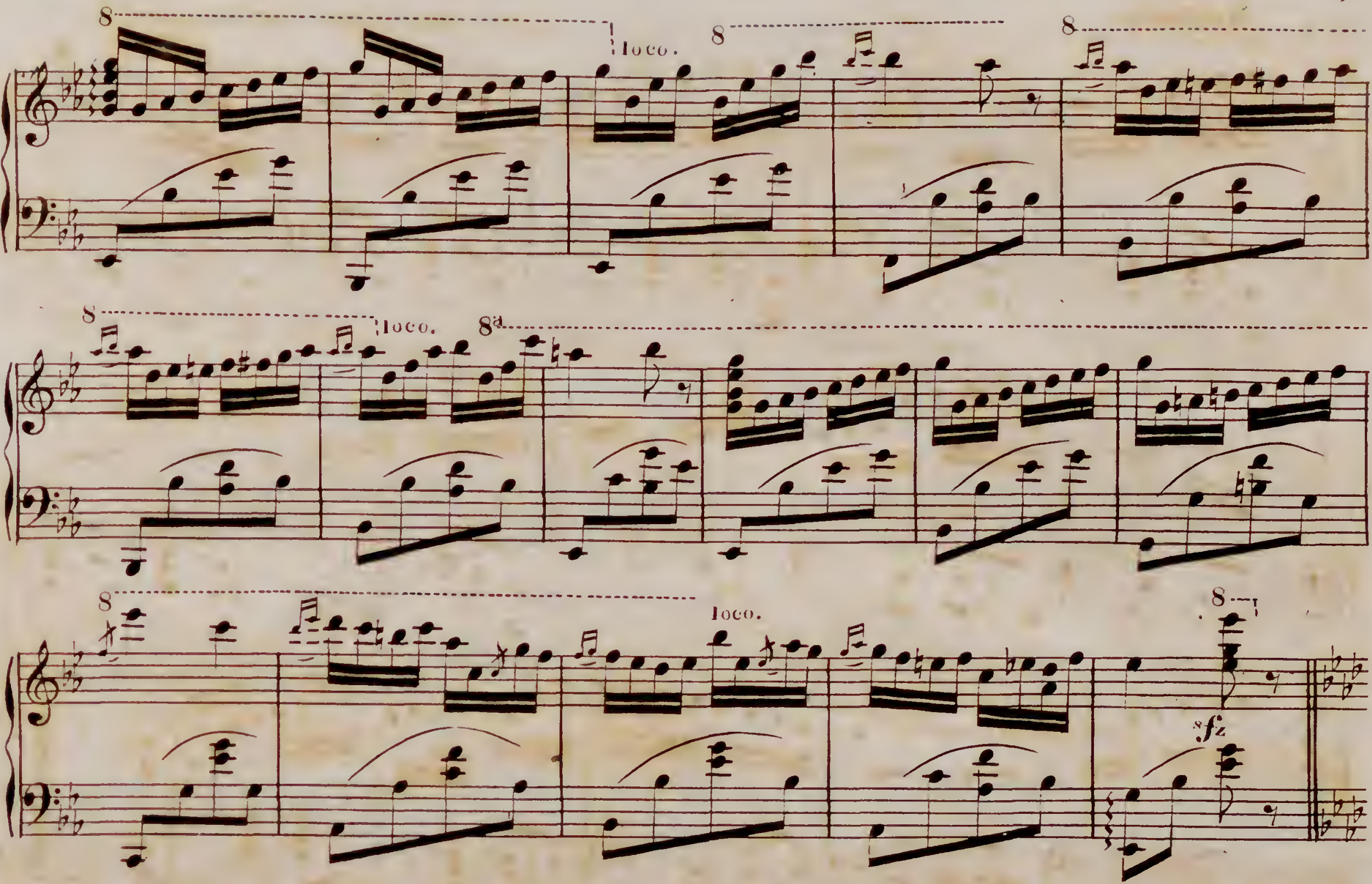

Brillante.

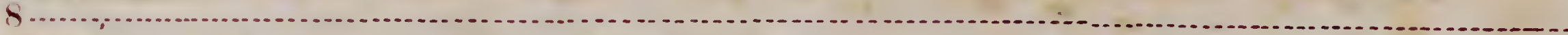
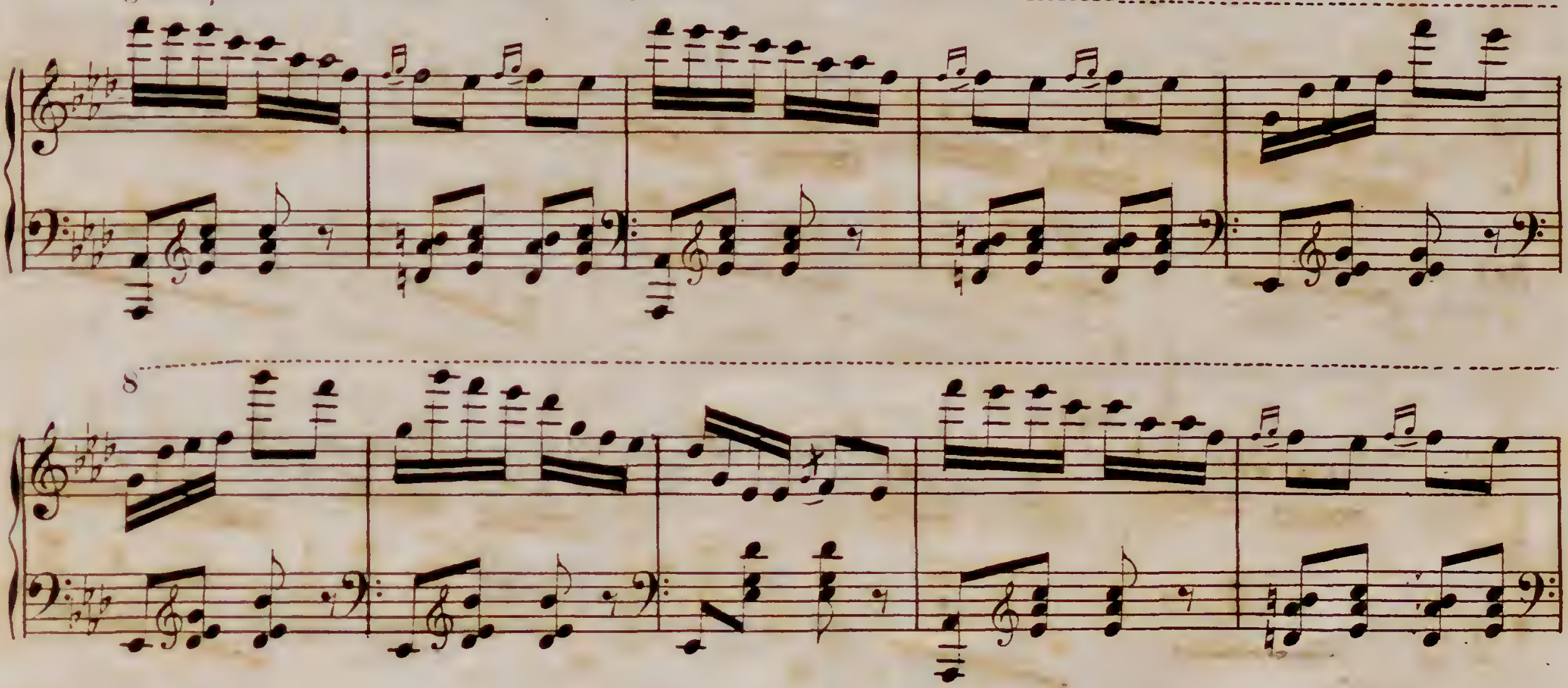

8

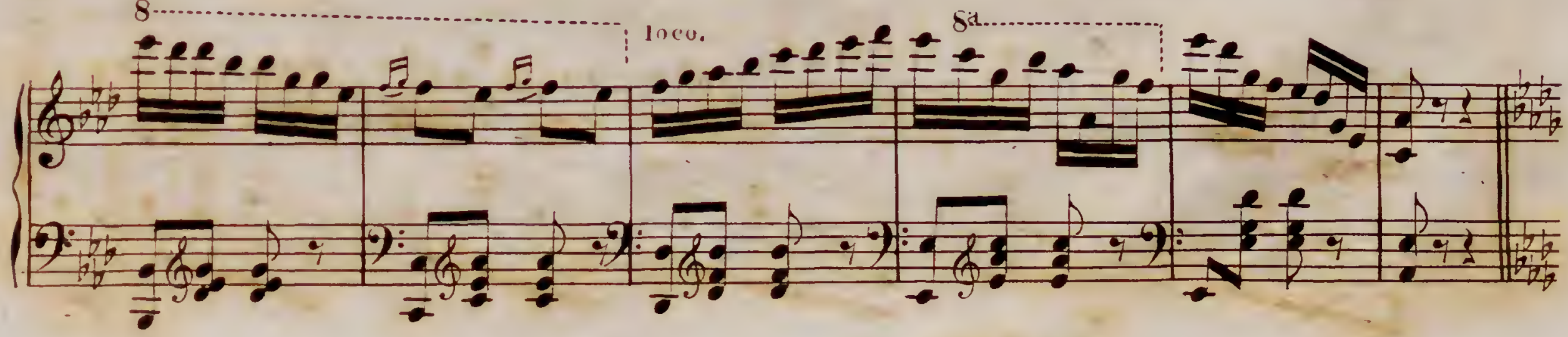

R M 130 

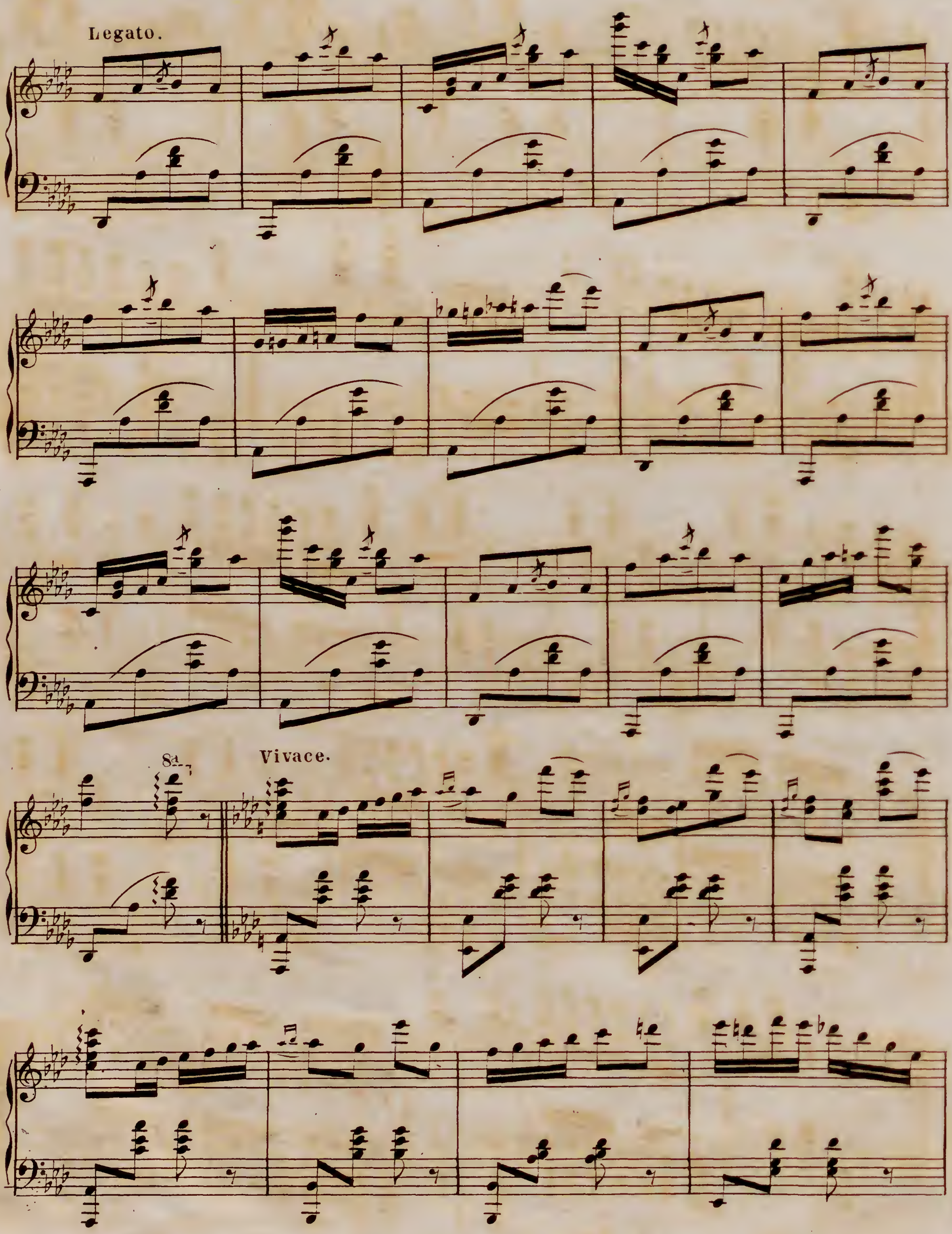

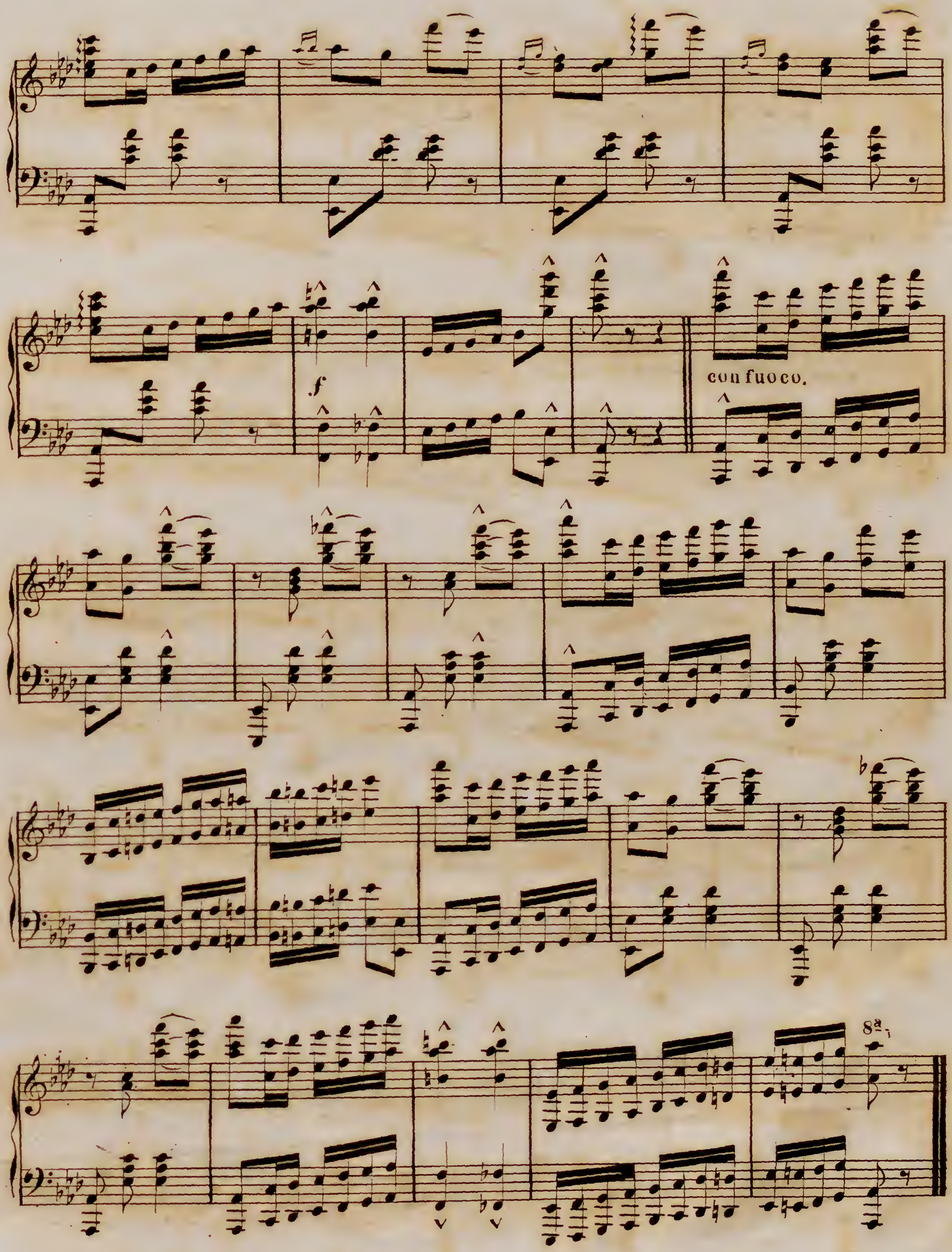

K N 130 
